\title{
Phase specific morphological changes induced by social experience in two forebrain areas of the zebra finch
}

\author{
Astrid Rollenhagen, Hans-Joachim Bischof* \\ Universität Bielefeld, Lehrstuhl Verhaltensforschung, Postfach 100131, D-33501 Bielefeld, FRG
}

Received 16 March 1994; revised 24 June 1994; accepted 24 June 1994

\begin{abstract}
We examined the changes of spine density in Golgi preparations of two different areas of the forebrain of the zebra finch, the ANC (Archi-Neostriatum caudale) and MNH (medial Neo-Hyperstriatum) during development, after transferring male birds from isolation to a social condition (exposure to a female for 1 week), and after a second isolation period. MNH and ANC are two of four brain regions which are strongly activated if a male bird is exposed to a female after some time of isolation. The results of our study can be summarized as follows. 1: a peak-decline trend is observed in $\mathrm{ANC}$, but not in MNH. 2: rearing conditions do not affect the development of both areas until day 70. 3: from 80 days of age, isolation leads to reduced spine density within ANC, but to enhanced spine density within MNH. 4: short social contact after isolation diminishes or eliminates the effects of isolation by an enhancement of spine density in ANC and a reduction of spine density within MNH. 5: the effects of short social rearing after isolation are reversible within $\mathrm{ANC}$, but not within $\mathrm{MNH}$. We presume that the alterations of spine density, which are induced by changes in social conditions, are restricted to ages older than 70 days by hormonal factors. We propose that the complexity of the ANC neuronal net follows the complexity of the social environment, and that the level of arousal is the most important factor influencing the complexity. We further suppose that the reduction of spines within MNH is the anatomical manifestation of an imprinting process, which has been shown to occur in the same experimental situation as we used it in our study.
\end{abstract}

Key words: Avian forebrain; Development; Plasticity; Dendritic spine; Golgi preparation; Zebra finch

\section{Introduction}

It is now generally accepted that environmental information contributes to the development of the central nervous system and can also change existing neuronal networks in adult animals. Principally, two different kinds of effects are observed: first, experience reduces the complexity of an existing network, and second, the complexity is enhanced. A reduction of neuronal connectivity has been shown in developing animals. Many brain areas show an initial increase of neuronal elements before or after birth, indicated for example by an increase in soma size, dendritic arborization, or density of dendritic spines $[4,12,13]$. After reaching a peak, the neuronal network is reduced drastically to the size also observed in adults $[4,26,29]$. This peak-decline trend is generally interpreted

\footnotetext{
* Corresponding author. Fakultät Biologie, Universität Bielefeld, Postfach 10013133501 , Bielefeld, FRG. Fax: (49) (521) 106-2998.
}

as a two step process, where first a redundant network is built, probably under genetic control [19]. The network is then shaped to its final form by a selection process, which preserves functionally effective synapses, but eliminates those which are not effectively driven by the periphery $[10,20,42]$. Evidence for such a selection process has been provided for example by experiments on the development of the neuromuscular junction $[9,10]$, and of ocular dominance and orientation selectivity within the visual cortex [15]. The same idea has also been applied to imprinting, an early learning process in birds $[1,2,41]$.

There is also ample evidence for the notion that experience can enhance the complexity of a given neuronal network. Rearing rats in an enriched instead of the normal laboratory environment, for example, results in an increase of neuronal elements of the visual cortex, indicated by an increase of the physical dimensions of the brain area, neuronal density and complexity, spine and synaptic density, or the increase of transmitter concentrations [18,32]. Social rearing, in contrast to isolated rearing, enhances 
spine densities in certain brain areas of so different species as jewel fish [11] or zebra finches [33].

Regressive and instructive processes, based on external stimulation, are not necessarily mutually exclusive. It has been argued that both contribute to the development of a given brain area $[3,31,35,39]$. It may be that both processes are working simultaneously, but at a given time, one of the processes can override the other, thus leading to the observed reduction or increase of network complexity.

This selective up- and downregulation of the two processes indicates that they are (at least partly) independent from each other, and this in turn suggests that they may have different functions. Although this has not been examined in detail, a survey of the existing literature suggests that selective stabilization mechanisms are predominantly involved in developmental plasticity, shaping neuronal nets which are not easily altered after they have been established in the course of a sensitive period [43]. In contrast, instructive alterations of neuronal tissue due to environmental influences do not seem to be restriced to development, and often seem to be reversible [14,17,34].

We examined the changes of spine density in two different areas of the forebrain of the zebra finch, the ANC (Archi-Neostriatum caudale) and MNH (medial NeoHyperstriatum) during development and after transferring male birds from isolation to a social condition or vice versa. These areas are two of four forebrain regions which are strongly activated if a male bird is aroused, e.g. by exposing it to a female after some time of isolation $[5,6]$. We have already shown [33] that at least one neuron type within ANC increases its spine density when male birds, isolated from 40 days to 100 days of age, were transferred to a female for 1 week. The other brain area, MNH, has been described to be involved in acoustic imprinting in chicks [41]. Wallhäusser and Scheich [41] showed that the spine density of a neuron type similar to that described by us for $\mathrm{ANC}$, is reduced by the imprinting procedure. Because there is strong evidence that imprinting occurs also in the situation described above, namely the first opportunity to court for a male which was isolated from independence until adulthood $[8,23,24]$ we were interested in the question whether $\mathrm{MNH}$ showed also alterations of spine density after the 1-week exposure to a female.

\section{Material and Methods}

A total of 60 male zebra finches (Taeniopygia guttata castanotis) was used for this study. The experimental design is illustrated in Fig. 1. All birds were reared by their natural parents in aviaries. At 40 days of age, part of the males were socially isolated while the others remained in the aviary. Four birds of each of the following age groups

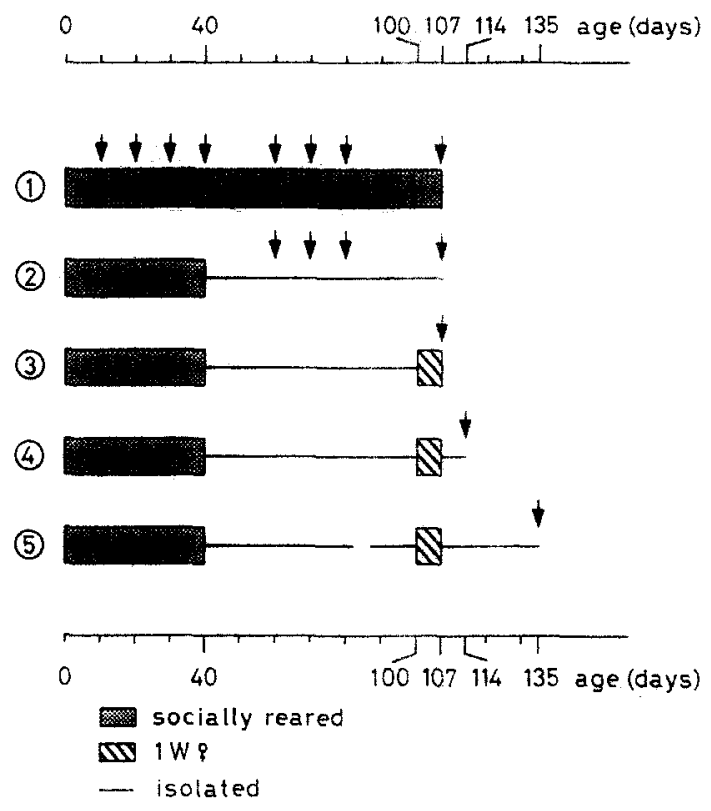

Fig. 1. Schematic drawing of the experimental design. Further explanations see text.

were taken for the examination of spine density changes during development: $10,20,30,40,60,70,80$, and 107 days of age from the socially reared animals, 60, 70, 80, and 107 days of age from the isolated animals.

For the second part of the study, four birds from the isolated group were exposed to a female from day 100 to day 107 and then processed for histology. Another four birds each were isolated for 1 or 4 weeks, respectively, subsequent to the exposure to the female, and thereafter processed for histology.

At the ages indicated above the birds were deeply anaesthetized by a high dose of nembutal and perfused with $0.9 \%$ saline, followed by $4 \%$ formalin. One hundred $\mu \mathrm{m}$ coronal vibratome sections were made after processing the brains according to a modification of the Bubenaite Golgi method [22]. Because $\mathrm{MNH}$ and ANC can be defined exactly only in 2-DG images, we used other structures, which could be seen in 2-DG as well as in Golgi preparations, as landmarks. ANC neurons were measured in sections which also contained the song control nucleus RA (nucleus robustus archistriatalis). In these sections, we measured neurons which were located in the neostriatum dorsolateral to the RA. For MNH, another song control area (area $X$ ) could be used as a landmark. MNH neurons were examined in the area dorsal to area $\mathrm{X}$, limited dorsally by the lamina hyperstriatica ( $\mathrm{LH})$ and ventrally by the lamina medialis dorsalis (LMD). At least five fully impregnated MNH and ANC type I neurons [33] (Fig. 2) from each bird were analyzed on drawings made with a drawing tube attached to a Zeiss microscope at a magnification of $1250 \times$ under oil. For the measurements, only those of the terminal sections of a dendrite were selected, 


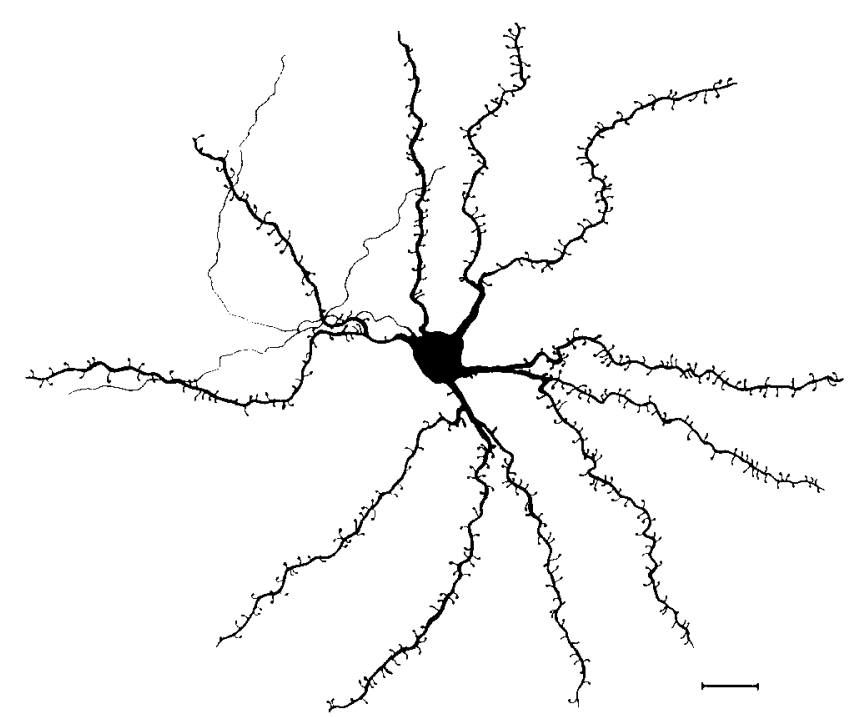

Fig. 2. Camera lucida drawing of an ANC neuron. $\mathrm{Bar}=10 \mu \mathrm{m}$.

which were parallel to the surface of the slide. Terminal sections were chosen because earlier studies have shown that these are most strongly affected by experience $[41,22,27,33]$. The selected sections (20 for each bird) were marked during drawing and the number of spines/ $10 \mu \mathrm{m}$ estimated with help of a graphics tablet.

Data collection was performed "blind", that is, coded slides were not uncoded until all measurement had been made. For statistical analysis, the mean of all measure- ments was calculated for each bird. This value was used as the basis for further statistics. Differences between age groups and different rearing conditions were then tested by the Kruskal-Wallis $H$-test with subsequent $U$-tests. As the computed calculations of significance provided by most statistical packages are incorrect for $n$ 's below 5, the significances (two-sided) were determined using a table provided by Siegel [36] for small samples.

\section{Results}

The results obtained in this study are depicted in Fig. 3. Fig. $3 \mathrm{a}$ shows the development of spine density of ANC neurons in aviary reared (solid line) and isolated birds (hatched line). Between days 10 and 20, a strong increase of spine density can be observed in the aviary reared animals (from $3.21 \pm 0.95$ to $5.58 \pm 0.83$ spines $/ 10 \mu \mathrm{m}$ ). The density decreases slightly, but not significant, from days 20 to $30(4.72 \pm 0.68$ spines $/ 10 \mu \mathrm{m})$. A peak is reached at day $40(8.51 \pm 0.59$ spines $/ 10 \mu \mathrm{m})$. Thereafter, the spine density decreases significantly until day $70(4.53 \pm 0.15$ spines $/ 10 \mu \mathrm{m})$. At day 80 , the spine density increases again $(7.74 \pm 0.36$ spines $/ 10 \mu \mathrm{m})$. This value is not significantly different from that measured in adult (107 day old) birds. Because the birds of the "isolated" group were not housed singly until day 40 , the first measurement for this group
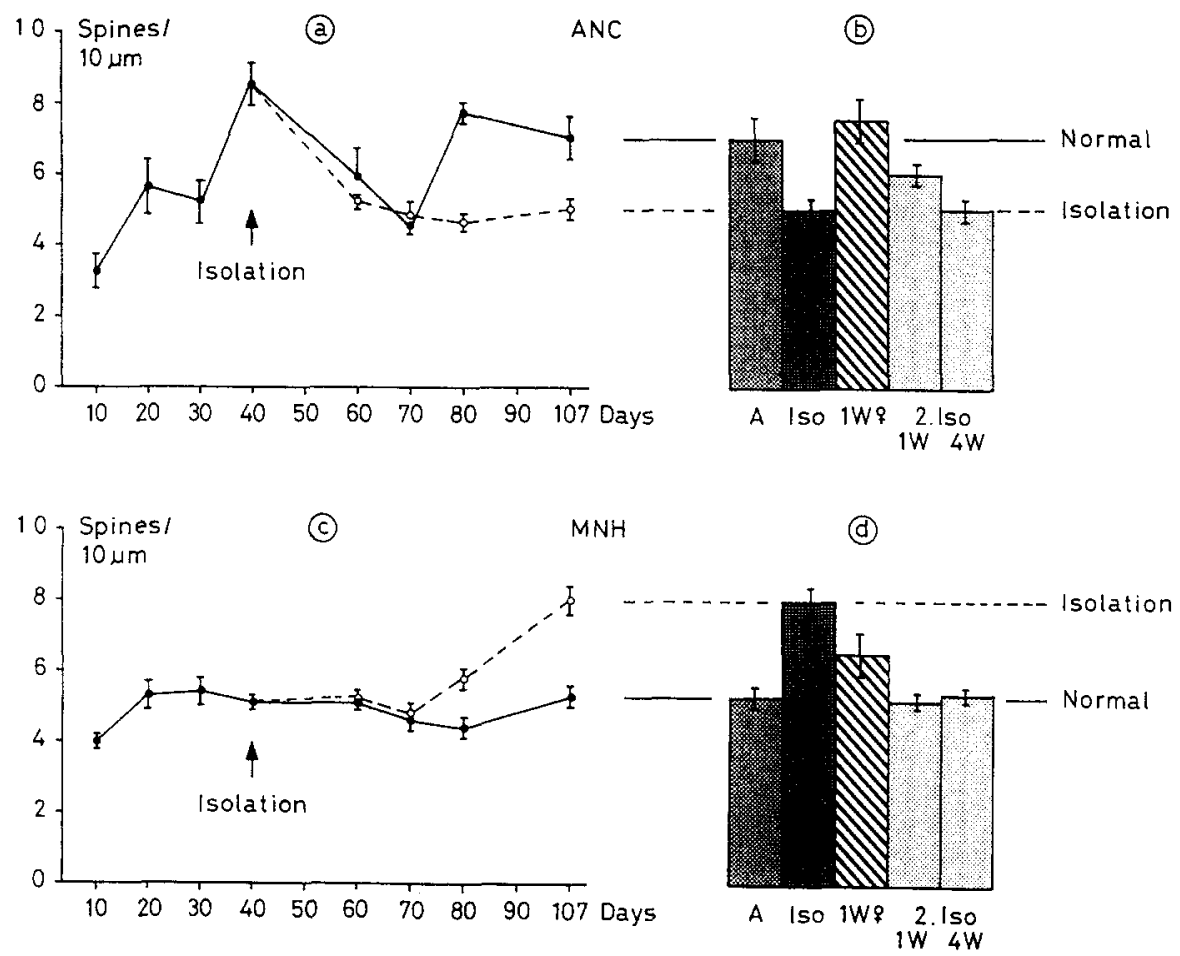

Fig. 3. Measurements of the mean spine densities $/ 10 \mu \mathrm{m}$ within ANC and MNH under the five different rearing conditions described in Fig. 1. a,c: development of spine density within ANC and MNH, respectively. b,d: spine densities obtained in the different groups descibed below for ANC and MNH, respectively. A, aviary; Iso, isolated; $1 \mathrm{~W}$ \% : exposure to a female for 1 week; 2. Iso, second isolation for either 1 or 4 weeks after exposure to a female for 1 week. 
was obtained at day 60 . At this day and day 70 , the measurements do not differ significantly from those obtained in the aviary reared animals (day 60: $5.05 \pm 0.16$ spines/ 10 $\mu \mathrm{m}$ isolated, $5.91 \pm 0.82$ socially, day $70: 4.77 \pm 0.15$ spines $/ 10 \mu \mathrm{m}$ isolated, $4.53 \pm 0.37$ spines $/ 10 \mu \mathrm{m}$ socially). However, at 80 days, where in the socially reared birds a second increase in spine density is observed, the isolated birds do not show a change compared to 70 days of age. In 107 day old birds, the difference between socially reared and isolated birds is maintained $(7.03 \pm 0.62$ spines $/ 10$ $\mu \mathrm{m}$ socially, $4.96 \pm 0.14$ spines $/ 10 \mu \mathrm{m}$ isolated; $P \leq 0.028$ ).

Fig. $3 \mathrm{~b}$ shows the effect of exposing an isolated bird to a female for 7 days after day 100 , and the effects of a second, 1- or 4-week isolation period thereafter. Exposing the birds to a female for 1 week results in spine densities similar to those obtained also in socially reared animals of the same age $(7.31 \pm 0.32$ spines $/ 10 \mu \mathrm{m}$ in birds exposed for 1 week, $7.03 \pm 0.62$ spines $/ 10 \mu \mathrm{m}$ in socially reared birds). If the birds were isolated again, the spine density decreased again to the level observed in isolated animals $(5.85 \pm 0.27$ spines $/ 10 \mu \mathrm{m}$ for 1 week of isolation, $4.88 \pm$ 0.30 spines $/ 10 \mu \mathrm{m}$ for 4 weeks of isolation, both values not significantly different from the "isolated" level).

The effects of social rearing or isolation on the spine density of MNH are depicted in Fig. 3c. Obviously, the development of spine density of socially reared animals within MNH is different from the development within ANC. There is a significant increase of spine density between days 10 and 20 , but thereafter, no significant change of spine density occurs until 107 days of age. Thus, adult levels are reached within MNH as early as 20 days, and no peak-decline trend can be observed as it was described above for ANC.

As within ANC, no significant differences were obtained between socially reared and isolated birds until day 70 . However, at day 80 , the spine density is significantly higher in isolated than in socially reared birds (isolated: $5.82 \pm 0.25$ spines $/ 10 \mu \mathrm{m}$, socially: $4.41 \pm 0.01$ spines $10 \mu \mathrm{m} ; P \leq 0.028)$. The difference increases until day 107 (isolated: $8.35 \pm 0.45$ spines $/ 10 \mu \mathrm{m}$, socially: $5.79 \pm 0.31$ spines $/ 10 \mu \mathrm{m} ; P \leq 0.028)$.

Fig. 3d shows that the effect of a 7 day contact is also very different for MNH compared to ANC. The spine densities are significantly lower than those obtained for isolated animals of the same age (1W : $6.31 \pm 0.55$ spines $/ 10 \mu \mathrm{m}$, isolated: $8.35 \pm 0.45$ spines $10 \mu \mathrm{m} ; P \leq 0.028)$. The density is still higher than that observed in socially reared animals of the same age, but the difference is not significant. In contrast to ANC, the change of spine density is not reversed by the subsequent second isolation. There is even a trend towards a further reduction of spine density to the level of socially reared animals.

\section{Discussion}

The most interesting finding of our study is the phase specific, differential effect of isolation on ANC and $\mathrm{MNH}$ neurons, and the fact that the effects of social rearing can be reversed in ANC, but not in MNH. However, we start with a short discussion of the other findings of our developmental study.

As already mentioned above. a peak decline trend is interpreted as a developmental process by which functionally ineffective synapses are eliminated from an excess of connections which are built under genetical control. Possibly, such a selection process may occur between days 40 and 70 in $\mathrm{ANC}$ and may be absent in MNH. It is more probable, however, that selective and instructive processes obscure each other in $\mathrm{MNH}$, while they are separated to a certain extent within ANC. Bischof and Herrmann $[4,21]$ proposed on the basis of a study on the development of sensory and motor areas in the zebra finch that the interplay between regressive and instructive processes obscures the peak decline trend more severely in central compared to peripheral brain areas. This would mean that ANC is located more peripheral than $\mathrm{MNH}$. Although the connections of both areas are at least partially known $[7,40]$, the anatomical evidence is as yet not sufficient to substantiate this notion.

In any case, it cannot be the social component of external experience which leads to the reduction of spine density within ANC from day 40 to day 70 , because isolation does not alter the spine counts during this time. It is obvious that both areas do not react to changes of the social environment earlier than 80 days of age. As yet, we can only speculate about the reason triggering the onset of sensitivity of the neuronal net of $\mathrm{ANC}$ and $\mathrm{MNH}$, respectively, to social stimuli. Zebra finches become sexually mature around 70 to 80 days from hatching, and several sexual hormones like testosterone, oestradiol, or progesterone peak between 70 and 80 days [28]. It may well be that changes in the two areas are possible only if the hormonal level of the animal is high. Whether this enhancement directly affects the neurons of $\mathrm{ANC}$ and $\mathrm{MNH}$, or whether the effect is indirect (hormonal enhancement induces a new social, namely sexual, interest in the bird, and thus a new quality of social interactions) has still to be determined. The most interesting finding of our study is the fact that isolation leads to spine density changes into opposite directions within $\mathrm{ANC}$ and $\mathrm{MNH}$, respectively. The change within ANC is easily explained by the framework provided by other studies showing that a social environment enhances spine densities in certain brain areas $[11,17,18]$ : if there is a lack of social stimulation, the spine density remains at the 70 day level. Our experiment with the 1 week exposure to a female shows that the 
adaptation to the new environment is very fast, and the "second isolation" experiment shows that it is reversible: The complexity of the ANC neuronal net thus follows the complexity of the social environment.

The cause and function of such changes is discussed controversely. Enhanced locomotion, stress, hormonal changes, neurochemical alterations and learning has been made responsible for the brain differerences found in animals reared in enriched compared to impoverished conditions [32]. We have indications from other experiments that enhanced arousal (induced by chasing) results in similar enhancements as observed by the exposure to a female [33]. We have also observed that the corticosterone level is enhanced during the 1 week exposure to the female (Oetting et al. in prep). In addition, the activity of ANC is enhanced by chasing as well as by courtship [5,6]. At present, we therefore favour the view that the enhanced level of arousal may be the most important variable inducing the increase of spine density within ANC. It has been shown that the amount of transfer of sensory information to higher brain areas is enhanced if the arousal of the animal is high [16,25]. Singer [37] demonstrated that the gating of sensory information takes place in thalamic relay nuclei under the control of the reticular formation. He proposed that this gating mechanism is responsible for the selection of those features of the environment which lead to plastic changes within the brain. Bischof and Herrmann $[5,6]$ demonstrated that the ANC and the MNH, as well as two other nuclei, show stronger activation in aroused animals. It is therefore plausible to presume that enhanced arousal, as it occurs in the social situation, may result in an enhanced stream of environmental information onto the ANC, and a more complex network may be required to handle this enhanced amount of information.

The decrease of spine density within $\mathrm{MNH}$ as a consequence of social experience and the increase due to isolation is more difficult to explain. A plausible idea may be that a social environment under normal circumstances (in the "socially reared" group) prevents an increase of the complexity of the neuronal network, which after 70 days of age may be induced by the same events which promote the responsiveness of both areas to social stimulation. This increase becomes obvious with isolation of the animal. In other words, there may be an instructive process being started in $\mathrm{MNH}$ after day 70, which is normally obscured by a selection process induced by the social environment. Our next experiment, exposing the isolated birds to a female for 1 week, supports this idea. It shows that a 1-week exposure to a female after isolation is sufficient to reduce the spine densities of MNH to values also obtained in socially reared animals. In this case, the instructive process started between days 70 and 80 is sepa- rated from the selective process, which is delayed due to the experimental design to the days 100-107. Our findings indicate that the changes within $\mathrm{MNH}$ are easiest explained within the "functional verification" theory developed by Hubel and Wiesel for the development of the visual cortex (see Section 1: Introduction). The similarity is even enhanced considering the results of our "second isolation" experiment: as in the visual cortex paradigm, the changes within MNH are not reversible. As yet, such selective processes have been found only in very few cases. Besides the studies concerning the development of the visual system [15], it has been shown in a song control nucleus of the mynah bird, occurring during the phase of learning of imitations [30], and in $\mathrm{MNH}$ of the chick as a consequence of acoustic imprinting [41]. Both processes, song learning and imprinting, are also very stable against further alterations, and they are also comparable in many other aspects to the phenomena of cortical development [2]. Because there is strong evidence that sexual imprinting occurs in exactly the situation we used in this study, namely the first exposure of a male to a female after reaching adulthood $[8,23,24]$, we suppose that the reduction of spines within $\mathrm{MNH}$ is the anatomical manifestation of this imprinting process.

\section{Acknowledgements}

Our thanks are due to Mrs. E. Geißler for preparing the figures and M. Voß for providing some of the Golgi preparations. Supported by the Deutsche Forschungsgemeinschaft (Bi 245/11).

\section{References}

[1] Bischof, H.-J., Imprinting and cortical plasticity: a comparative review, Neurosci. Biobehav. Rev., 7 (1983) 213-225.

[2] Bischof, H.-J., Environmental influences on carly development: a comparison between imprinting and cortical plasticity. In P.P.G. Bateson, and P.H. Klopfer (Eds.), Perspectives in Ethology. Vol. 6. Mechanisms, Plenum, New York, 1985, pp. 169-217.

[3] Bischof, H.-J., Neuronal plasticity in the development of birds. In H. Rahmann (Ed.), Progress in Zoology', 37. Fundamentals of Memory Formation: Neuronal Plasticity, Gustav Fischer Verlag, Stuttgart, 1989, pp. 117-131.

[4] Bischof, H.-J. and Herrmann, K., Ontogenetic development of sensory and song control areas in the zebra finch brain, Behav. Brain Res., 12 (1984) 171-172.

[5] Bischof, H.-J. and Herrmann, K., Arousal enhances ${ }^{1+} \mathrm{C}$ Deoxyglucose uptake in four forebrain areas of the zebra finch, Behav. Brain Res., 21 (1986) 215-221.

[6] Bischof, H.-J. and Herrmann, K., Isolation dependent enhancement of $2-{ }^{14} \mathrm{C}$ Deoxyglucose uptake in the forebrain of zebra finch males, Behav. Neural Biol., 49 (1988) 386-397.

[7] Bischof, H.-J., Herrmann, K., Engelage, J., Niemann, J. and Church, E., Connections and function of an "arousal"area of the caudal forebrain of zebra finches, Soc. Neurosci. Abstr., 14 (1988) 38.8 . 
[8] Bischof, H.-J. and Clayton, N., Stabilization of sexual preferences by sexual experience in male zebra finches (Taeniopygia guttata castanotis), Behaviour, 118 (1991) 145-155.

[9] Brown, M.C., Jensen, J.K.S. and Van Essen, D., Polyneuronal innervation of skeletal muscle in new-born rats and its elimination during maturation, J. Physiol., 261 (1976) 387-422.

[10] Changeux, J.P. and Danchin, A., Selective stabilization of developing synapses as a mechanism for the specification of neuronal networks, Nature, 264 (1976) 705-712.

[11] Coss, R.G. and Globus, A., Spine stems on tectal interneurons in jewel fish are shortened by social stimulation, Science, 200 (1978) 787-789

[12] Cragg, B., The development of synapses in kitten visual cortex during visual deprivation, Exp. Neurol, 46 (1975) 445-451.

[13] Cragg, B., The development of synapses in the visual system of the cat, J. Comp. Neurol., 160 (1975) 147-166.

[14] Ferrer,I., Cambios morphologicos en la corteza cerebral de retones somtidos a medios enriquecidos y a medos empobrecidos en estimulos sensoriales y su posterior recuperation, Arch. Neurobiol., 46 (1983) 177-182.

[15] Fregnac, Y. and Imbert, M., Development of neuronal selectivity in primary visual cortex of cat, Physiol. Rev., 64 (1984) 35-434.

[16] Gonzalez-Lima, F. and Scheich, H., Classical conditioning enhances auditory 2-Deoxyglucose patterns in the inferior colliculus, Neurosci. Lett., 51 (1984) 79-84.

[17] Green, E.J. and Greenough, W.T., Altered transmission in dentate gyrus of rats reared in complex environments: evidence from hippocampal slices maintained in vitro, Proc. Natl. Acad. Sci., 82 (1986) 4549-4552.

[18] Greenough, W.T. and Green, E.J., Experience and the changing brain. In J.L. Mc Gaugh, J.G. March and S.B. Kiesler (Eds.). Aging: Biology and Behavior, Academic Press, New York. 1981, pp. $160-200$.

[19] Hamori, J., Plasticity during neuronal differentiation: an experimental study of developing synapses and neuronal networks. In $Y$. Tsukuda and B.W. Agranoff (Eds.), Neurobiological Basis of Leaming and Memory, Wiley, New York, 1980, pp. 1-18.

[20] Hebb, D.O., The Organization of Behaviour, New York, 1949

[21] Herrmann, K. and Bischof, H.-J., Delayed development of song control nuclei is related to behavioral development, $J$. Comp. Neurol., 245 (1986) 167-175.

[22] Herrmann, K. and Bischof, H.-J., Development of neurons in the ectostriatum of normal and monocularly deprived zebra finches: a quantitative Golgi study, J. Comp. Neurol., 277 (1988) 141-154.

[23] Immelmann, K., Pröve, R., Lassek, R., Bischof, H.-J., Influence of adult courtship experience on the development of sexual preferences in zebra finch males, Anim. Behav., 42 (1991) 83-89.

[24] Kruijt, J.P. and Meeuwissen, G.B., Sexual preferences of male zebra finches: effects of early and adult experience, Anim. Behar., 42 (1991) 91-102.

[25] Livingstone, M. and Hubel, D.H., Effects of sleep and arousal on the processing of visual information in the cat, Nature, 291 (1981) $554-561$.

[26] Murphy, E.H., Critical periods and the development of the rabbit visual cortex. In J. Stone, B. Dreher and D.H. Rappaport (Eds.)
Development of the Visual Pathways in Mammals, Allan R. Liss, New York, 1984, pp. 429-469.

[27] Patel, S.N., Rose, S.P.R. and Stewart, M.G., Training induced dendritic spine density changes are specifically related to memory formation processes in the chick, Gallus domesticus, Brain Res., 463 (1988) $168-173$.

[28] Pröve, E., Hormonal correlates of behavioral development in malc zebra finches. In J. Balthazart, E. Prove and R. Gilles (Eds.), Hormones and Behavior in Higher Ventebrates, Springer Verlag, 1983. pp. 368-374.

[29] Racic, P., Development of the Primate Visual System. In P. Bagnoli and W. Hodos (Eds.), The Changing Visual System. Maturation and Aging in the Central Visual System, Nato ASI Series A Life Sciences. Vol. 222, Plenum Press, New York. London, 1991. pp. 1-10.

[30] Rausch, G. and Scheich, H., Dendritic spine loss and enlargement during maturation of the speech control system in the mynah bird (Gracula religiosa), Neurosci. Lett., 29 (1987) 129-134.

[31] Rauschecker. J. and Singer. W, The effects of early visual experience on the cat's visual cortex and their possible explanation by Hebb synapses, $J$. Physiol. 310 (1981) 215-239.

[32] Renner, J.M. and Rosenzweig, M.R.. Enriched and Impoverished Environmens: Effects on Brain and Behavior. Springer Verlag. New York, 1987.

[33] Rollenhagen, A. and Bischof, H.-3, Rearing conditions affect neuron morphology in a telencephalic area of the zebra finch. NewroReport, 2 (1991) 711-714.

[34] Rosenzweig, M.R., Bennett, C.L., Diamond, M.C., Brain changes in response to experience, Sci. Am. 226 (1962) 77-95

[35] Scheich, H. and Braun. K., Synaptic selection and calcium regulation: common mechanisms of auditory filial imprinting and vocal learning in birds? Verh. Dtsch. Zowl. Ges., 81 (1989) 77-95.

[36] Siegel, S.. Nichtparametrische statistische Methoden, Fachbuchhandlung für Psychologic, Frankfurt am Main, 1976.

[37] Singer, W., Control of thalamic transmission by corticofugal and ascending reticular pathways in the visual system, Physiol. Rev., 57 (1977) $386-420$.

[38] Singer, W., Central-core control of visual cortex functions. In F.O. Schmitt and F.G. Worden (Eds.). The Neurosciences Fourth Study Program. MIT Press, Cambridge, MA, 1979. 1093-1110.

[39] Singer, W., Learning to see: mechanisms in experience dependen development. In P. Marler and H.S. Terrace (Eds.), Dahlem Konferenzen. Life Science Report 29. Springer Verlag, Berlin. 1984. pp. $461-478$.

[40] Wallhäusser-Franke, E., Anatomisthe Korrelate der akustischen Fitialprägung im ZNS von Haushuhnkizken (Gallus domesticus) und die Verbindungen der beteiligten Gebiete. Thesis, Univ. of Darmstadt. 1989.

[41] Wallhäusser, E. and Scheich. H. Auditory imprinting leads to differential 2-deoxyglucose uptake and dendritic spine loss in the chick rostral forebrain, Dev. Brain Res., 31 (1987) 29-44.

[42] Wiesel, T.N., Postnatal development of the visual cortex and the influence of environment, Nature. 299 (1982) 582-591.

[43] Wiesel, T.N. and Hubel, D.H., Extent of recovery from the effects of visual deprivation in kittens,. . Neurophysiol., 28 (1965) 10601072. 